\title{
La Heterogeneidad del Alfabetismo en Salud y el Consentimiento Informado en Chile
}

\section{The Case Against Template Informed Consent Procedures in Biomedical Research: Heterogeneity in Health Literacy in Chile}

\author{
Oscar Saavedra-Dahm \\ Paula Solar \\ Hernán Díaz \\ Astrid Mandel \\ María Casado \\ Pedro Orihuela \\ María Rivera \\ Universidad de Santiago de Chile, U SACH. \\ Luis Velásquez \\ Universidad Nacional Andrés Bello, Chile \\ Hugo Cardenas \\ Universidad de Santiago de Chile, USACH \\ Centro para el Desarrollo de la Nanociencia y la Nanotecnología (CEDENNA) \\ (Rec:10 de julio de 2012 / Acep: 04 de septiembre de 2012 )
}

\begin{abstract}
Resumen
Se examinó el alfabetismo en salud en Chile con el fin de determinar si se pueden usar procedimientos de consentimiento informado estándares en esta población.

Se evaluó el alfabetismo en salud con la versión abreviada de la prueba SAHLSA. Los resultados se expresaron como el porcentaje de respuestas correctas en cada prueba.

El promedio global de respuestas correctas fue $85.4 \pm 13.5 \%$ (media aritmética \pm desviación estándar, $n=762$ ). Hubo diferencias importantes entre los subgrupos examinados. El nivel más bajo de alfabetismo en salud se detectó en pescadores artesanales y sus familias y en estudiantes de liceos públicos, y el más alto en estudiantes universitarios y madres pobladoras atendidas en el sistema público de salud.

Los resultados muestran la necesidad que los procedimientos de consentimiento informado tomen en cuenta la heterogeneidad del alfabetismo en salud de la población chilena.

Palabras clave: consentimiento informado, alfabetismo en salud, bioética.
\end{abstract}

\begin{abstract}
Health literacy was examined in Chile to assess whether it is homogenous enough to allow the use of "templates" for informed consent, and to identity subgroups that may need special consideration when recruited for research because of their low health literacy abbreviated SAHLSA test of health literacy was used. Results were expressed as percent of correct answers out of the 50 items of the SAHLSA test.

There was high health literacy with $85.4 \pm 13.5 \%$ (arithmetic mean \pm standard deviation, $n=762$ ) of correct answers. There were important differences between groups, with lower scores in artisanal fishermen families and high-school students attending public schools, and higher scores in university students and mothers attending the public health system.

Results show that a case by case approach is probably more appropriate when seeking informed consent in this population because of the variability of health literacy.

Keywords: informed consent, health literacy, bioethics.
\end{abstract}

Correspondence: Prof. Hugo Cárdenas y Prof. Oscar Saavedra. Universidad de Santiago de Chile, Casilla 40 Correo 33, Santiago, Chile. ZIP Code 7190006. Phone 56-2-7181087.Email: oscar.saavedra@usach.cl,hugo.cardenas@usach.cl

Finantial support: DICYT of USACH and Proyecto Basal FB0807-CEDENNA (Centro para el Desarrollo de la Nanociencia y la Nanotecnología) 


\section{Introduction}

Informed consent is one of the most discussed concepts in bioethics. Despite the practice of seeking and reporting informed consent now has become universally accepted, this has not always been the case. For example, not long ago the development of routine prenatal testing led some authors to question whether informed consent was necessary at all for these procedures (Press \& Browner, 1995). A recent review on published cluster randomized trials found that $31 \%$ of the papers failed to report whether consent was sought before the trial (Taljaard, McRae, Weijer, Bennett, Dixon, Taleban \& Grimshaw, 2011).

Requirements and conditions for a valid informed consent are somehow different in clinical practice and research because of the legal framework and limitations of informed consent to medical treatment (Del Carmen \& Joffe, 2005). Geller, Strauss, Bernhardt \& Holtzman (1997) highlighted the problematic nature of informed consent in any clinical context where there is residual uncertainty about the benefits and risks of tests, concluding after surveying women's opinions that informed consent ought to be individualized based on patients beliefs and preferences. However, the practice of a unified informed consent procedure and document is deeply rooted in clinical research, and "templates" for informed consent in clinical trials have been proposed (for example see Koyfman, McCabe, Emanuel \& Grady, 2009).

Quality of informed consent has been reported to be different between developing and developed countries, but recent evidence points to a more nuanced picture, with comprehension varying among participants in both groups of countries (Mandava, Pace, Campbell, Emanuel \& Grady, 2012). Because the practice of informed consent is today universally accepted, differences between developed and developing countries are probably related to differing degrees of empowerment for people. In Chile, most of clinical and biomedical research is done in public hospitals, and recently informed consent and institutional review boards became a legal requirement to obtain permission to initiate a research project.

The Ethics Committee at the Universidad de Santiago de Chile has examined many research projects during the last years revealing that most persons to be recruited as study subjects did belong to disadvantaged groups exhibiting low socioeconomic and educational status. Despite this country has a high literacy rate (Maturana \& Cardenas, 2008), disparity in access to quality education during primary and high school is recognized as a problem that has not been appropriately addressed. This raises the possibility that despite having good basic literacy skills, disadvantaged groups in the Chilean society may not have appropriate comprehension capabilities regarding health issues like those involved in current biomedical research they are asked to volunteer for.

We used a recently described standardized test for quantification of health literacy (Lee, Bender, Ruiz \& Cho, 2006) to examine health literacy in subgroups of the Chilean society in order to assess (1) whether health literacy it is homogenous enough to allow the use of "templates" for informed consent, and (2) to identity subgroups that may need special consideration when recruited for biomedical research because of their low health literacy.

\section{Methods}

\section{Instruments}

Health literacy was assessed by the abbreviated version of the Short Assessment of Health Literacy for Spanishspeaking Adults (SAHLSA) (Lee et al., 2006). This test examines the understanding of commonly used medical terms. Volunteers were asked to associate each of 50 terms to another word of similar meaning to demonstrate comprehension. Result for each individual test was expressed as percentage of correct answers out of the 50 terms.

\section{Participants}

Subjects were recruited at (1) a small coastal town of artisanal fishermen and their families located in Northern Chile ( $n=97)$; (2) an outpatient reproductive health clinic for low income families attending patients from the public health system $(n=104)$; (3) first year students enrolled at the Universidad de Santiago de Chile (a public university), excluding life science colleges ( $n=326$ ); and (4) high-school students in their last year attending private, semi-private (partial funding from the government) and public schools $(n=235)$.

\section{Procedures}

University and high-school students were asked to respond the SAHLSA test presented in a single printed page format where they had to select and write the correct option for each one of the 50 items of the test. This is a format they are accustomed to and there were no complains or unexpected difficulties during application of the test. For the participants not enrolled in formal education, i.e., the fishermen families and mothers attending the public health system, each item of the SAHLSA test was presented in a separate card containing the test word and the options for answer, and the examiner read aloud the word and the possible matches while the volunteer read the card. Afterwards, the volunteer indicated by mouth or finger pointing his/ her answer. 
Results across groups were compared by analysis of variance. The relationship between health literacy and schooling was examined by linear regression. Statistical analysis was performed by the Minitab software (15.1.20.0).

This project was approved by the Ethics Committee of the Universidad de Santiago. Subjects were thoroughly informed about the project and their participation, and informed consent was obtained before the SAHLSA tests.

\section{Results}

The grand mean of all tests was $85.4 \pm 13.5 \%$ (arithmetic mean \pm standard deviation, $n=762$ ). The distribution of the results reveals wide variability with values ranging over the whole scale of SAHLSA results. Most respondents obtained more than $80 \%$ of correct answers (Figure 1).

Subgroups of respondents showed disparity in SAHLSA results. The group with the lowest mean score were the fishermen and their families, followed in ascending order by the high-school students, the users of the outpatient reproductive health clinic and the first year University students, respectively (Figure 2, Table 1). This last group exhibited, in addition to the highest mean score, the lowest variability with almost no respondent with less that $80 \%$ correct answers.

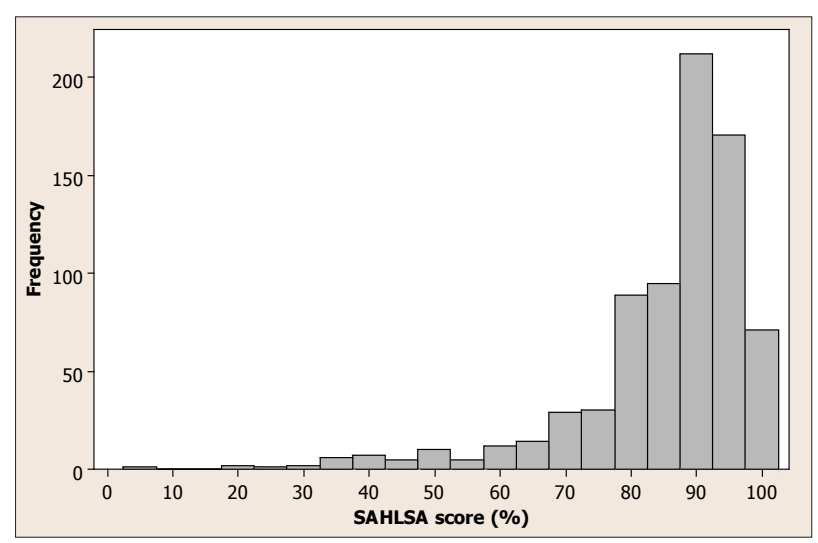

Figure 1. Distribution histogram of the SAHLSA test results obtained in the Chilean population. Results correspond to the percentage of correct answers out of the 50 items of the test.

Table 1. Health literacy according to the subgroup of the Chilean population.

\begin{tabular}{lccc}
\multicolumn{4}{c}{ Chilean population. } \\
Subgroup & Mean & SE & $\mathrm{n}$ \\
\hline Fishermen families & 67.2 & 2.2 & 97 \\
High School students & 83.3 & 0.7 & 235 \\
Outpatient Clinic patients & 89.9 & 0.8 & 104 \\
Public University students & 90.9 & 0.3 & 326 \\
\hline
\end{tabular}

Note. The subgroup of fishermen families displayed a lower mean score in the SAHLSA test that the other groups $(\mathrm{p}<0.05)$. High school students had lower SAHLSA score than University students $(\mathrm{p}<0.05)$.
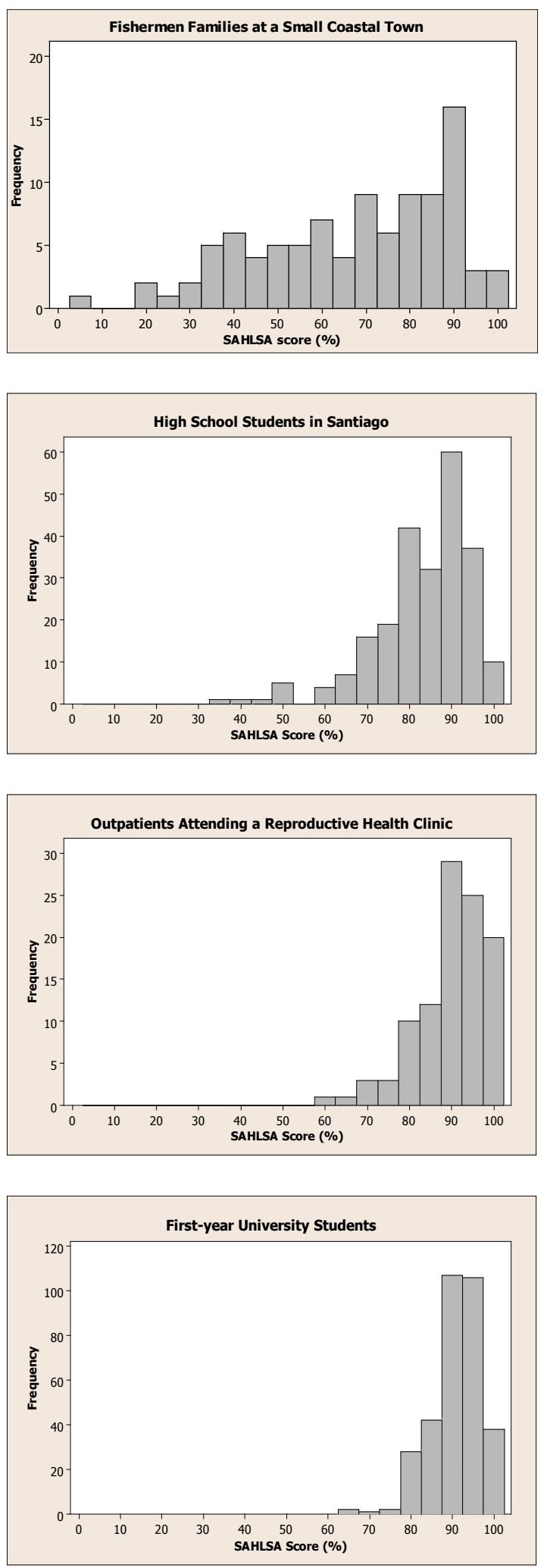

Figure 2. Distribution histogram of the SAHLSA test results according to the subgroup of the Chilean population. Results correspond to the percentage of correct answers out of the 50 items of the test. 
There was no statistically significant difference between the University students and the mothers attending the reproductive health clinic seeking contraceptive assistance and pediatric services for their babies (up to 3 year old), but they both obtained a slight but statistically significant higher score than the high-school students mostly because of an important proportion of tests falling below $80 \%$ of correct answers in this last group.

Results from high-school students displayed a straightforward relationship with ownership system of the school (Table 2). Highest mean SAHLSA score was found in students attending private schools, and the lowest in public schools that in Chile are administered by the mayor and the city council of the respective county. Students affiliated to private schools belong primarily to upper-class families, and students attending public schools come almost entirely from lower-class families. The semi-private schools are private but subsidized by the government and their students come from middle-class families.

Table 2. Health literacy in students according to the ownership system of the high school they are enrolled at in Santiago.

\begin{tabular}{lccc}
\hline Ownership of & Mean & SE & $\mathrm{n}$ \\
\hline Public & 79.9 & 1.1 & 133 \\
Semi-private & 84.0 & 1.1 & 48 \\
Private & 92.1 & 0.7 & 54 \\
\hline
\end{tabular}

Note. Differences between the groups in the SAHLSA test results were statistically significant $(\mathrm{p}<0.05)$.

The fishermen and their families obtained a statistically significant lower mean SAHLSA score than all the other groups (Table 1). In addition, their results exhibited wide variability with a flat distribution ranging from 5 to $100 \%$ of correct answers and most of respondents obtaining less than $80 \%$ (Figure 2).

The relationship between schooling and results of the SAHLSA test was examined by linear regression in the group of fishermen and their families because this subgroup exhibited the needed wide range of variation in schooling required for this analysis. There was a small but statistically significant positive linear regression of health literacy over schooling (data not shown).

No significant relationship was found between the SAHLA scores and gender.

\section{Discussion}

Despite health literacy is required to meet "understanding", one of the essential elements of informed consent to therapeutic and experimental procedures in medicine and biomedical research (Del Carmen \& Joffe, 2005; Cañete,
Guilhem \& Brito, 2012), assessment of health literacy is not common practice during informed consent procedures. Template informed consent documents are usually applied to volunteers grouped according to factors like medical treatment and health condition but not literacy (for example see Koyfman et al. 2009).

Chile is regarded as one of the countries with high literacy rate in the region (Maturana \& Cardenas, 2008), and results of this paper points to what appears to be proper health literacy (i.e., mean score in the SAHLSA test of $85 \%$ ). However, results also demonstrate high heterogeneity in the scores of the health literacy test.

Results support the use of the SAHLSA test to assess health literacy in the Chilean population because it detected differences between groups and those differences are in concordance with what is to be expected according to the educational level of the groups. The highest scores were obtained by first year University students and the lowest from the group with lowest schooling: the fishermen and their families in the small coastal town in Northern Chile. This village is located near the North border with Peru about $2000 \mathrm{~km}$ from Santiago, the capital city of Chile. High-school students attending private institutions in Santiago obtained higher scores than students enrolled in the public system, which parallels the performance of those institutions in national standardized tests of educational achievement (SIMCE, 2012). The relationship between SAHLSA scores and educational level was examined within the sample of fishermen and their families because this group exhibited the whole range of schooling from 0 to 12 years (i.e., elementary plus high-school) with a few individuals with some level of higher education. As expected for a test sensitive to understanding of healthrelated printed words, there was a statistically significant linear correlation between scores in the SAHLSA test and years of formal schooling.

Results then reveal low level and high variability of health literacy in subgroups of the Chilean population which implies that using standardized informed consent procedures and documents may not be proper for everybody in this population.

Most if not all medical research in Chile is performed in patients and healthy volunteers recruited at public hospitals that attend low-income families. However, health literacy of mothers attending the outpatient family planning clinics in Santiago was identical to first year University students, which indicates that it cannot be assumed that low income patients do not have health literacy skills to provide a valid informed consent. Those mothers lived in the capital city of the country and they have access to a public health system that provides education regarding health care of their children. Situation was the opposite for the families living in the small coastal fishermen town where they do not have 
medical services and most people had not graduated from high-school.

It may be concluded that a case by case approach is probably more appropriate when seeking informed consent in this population, in order to take into consideration the individual understanding capabilities. Subjects living in rural towns and youngsters from disadvantaged families require special consideration by clinician/researchers when informed consent is sought, and by the Ethics Committees when informed consent procedures and documents are examined.

The issue addressed in this paper by no means implies that proper informed consent in clinical practice or research is guaranteed after a short test for health literacy. The SAHLSA test was designed to evaluate basic comprehension capabilities of Hispanic patients not fluent in English and seeking attention from the public health system in the US, and it may prove to be a useful tool in a different setting like Chile.

However, the complex ethical challenges raised by modern biomedicine like genetic and genomic research (Simon, Shinkunas, Brandt \& Williams, 2012) or the use of residual biological material (Gefenas, Dranseika, Serepkaite, Cekanauskaite, Caenazzo, Gordijn \& Yuko, 2012) are just beginning to be defined and they need to be thoroughly addressed locally in developing countries like Chile, where clinical trials and research have traditionally been carried out in disadvantaged communities.

\section{References}

Cañete, R., Guilhem, D., \& Brito, K. (2012). Consentimiento informado: algunas consideraciones actuales. Acta Bioethica, 18, 121-127.

Del Carmen, M.G., \& Joffe, S. (2005). Informed consent for medical treatment and research: a review. The Oncologist, 10, 636-641.

Gefenas, E., Dranseika,V., Serepkaite, J., Cekanauskaite, A., Caenazzo, L., Gordijn B., Pegoraro, R. Yuko, E. (2012). Turning residual human biological materials into research collections: playing with consent. Journal of Medical Ethics, 38, 351-355. doi:10.1136/medethics-2011-100113.

Geller, G., Strauss, M., Bernhardt, B.A., \& Holtzman, N.A. (1997). "Decoding" informed consent. Insights from women regarding breast cancer susceptibility testing. The Hasting Center Report, 27, 28-33.

Koyfman, S.A., McCabe, M.S., Emanuel, E.J., \& Grady, C. (2009). A consent form template for phase I oncology trials. IRB: Ethics \& Human Research, 31, 1-8.

Lee, S-Y.D, Bender, D.E., Ruiz, R.E., \& Cho, Y.I. (2006). Development of an easy-to-use Spanish health literacy test. Health Services Research, 41, 1392-1412.

Mandava, A., Pace, C., Campbell, B., Emanuel, E., \& Grady, C. (2012). The quality of informed consent: mapping the landscape. A review of empirical data from developing and developed countries. Journal of Medical Ethics. 38, 356-365. doi:10.1136/medethics-2011-100178.

Maturana, M., \& Cardenas, H. (2008). Chile chapter. In Carolyn D'Avanzo (Ed.), Mosby's Pocket Guide to Cultural Health Assessment (pp. 153158). Fourth Edition. Mosby, Inc. (affiliated to Elsevier, Inc.): USA

Press, N., \& Browner, C.H. (1995). Risk, autonomy, and responsibility. Informed consent for prenatal testing. The Hasting Center Report, 25, 9-12.

SIMCE (2012). Sistema de Medición de Calidad de la Educación. available at www.simce.cl.

Simon, C., Shinkunas, L.A., Brandt, D., \& Williams, J.K. (2012). Individual genetic and genomic research results and the tradition of informed consent: exploring US review board guidance. Journal of Medical Ethics, 38, 417-422. doi:10.1136/medethics-2011-100273.

Taljaard, M., McRae, A.D., Weijer, C., Bennett, C., Dixon, S., Taleban J. \& Grimshaw, J.M. (2011). Inadequate reporting of research ethics review and informed consent in cluster randomized trials: review of random sample of published trials. British Medical Journal, 342, 1-9. doi:10.1136/bmj.d2496. 
